\title{
Clinicopathological Characteristics and Surgical Outcomes of Crohn Disease-Associated Colorectal Malignancy
}

\author{
Yoo Na Lee ${ }^{1}$, Jong Lyul Lee ${ }^{1}$, Chang Sik Yu ${ }^{1}$, Jong Beom Kim${ }^{1}$, Seok-Byung Lim ${ }^{1}$ In Ja Park ${ }^{1}$, \\ Young Sik Yoon ${ }^{1}$, Chan Wook Kim ${ }^{1}$, Suk-Kyun Yang ${ }^{2}$, Byong Duk Ye², Sang Hyoung Park ${ }^{2}$, Jin Cheon Kim ${ }^{1}$ \\ Departments of ${ }^{1}$ Surgery and ${ }^{2}$ Gastroenterology, Asan Medical Center, University of Ulsan College of Medicine, Seoul, Korea
}

Purpose: Carcinoma arising from Crohn disease (CD) is rare, and there is no clear guidance on how to properly screen for at-risk patients and choose appropriate care. This study aimed to evaluate the clinicopathological characteristics, treatment, and oncologic outcomes of CD patients diagnosed with colorectal cancer (CRC).

Methods: Using medical records, we retrospectively enrolled a single-center cohort of 823 patients who underwent abdominal surgery for CD between January 2006 and December 2015. CD-associated CRC patients included those with adenocarcinoma, lymphoma, or neuroendocrine tumors of the colon and rectum.

Results: Nineteen patients (2.3\%) underwent abdominal surgery to treat CD-associated CRC. The mean duration of CD in the CD-associated CRC group was significantly longer than that in the benign CD group (124.7 \pm 77.7 months vs. $68.9 \pm 60.2$ months, $\mathrm{P}=0.006)$. The $\mathrm{CD}$-associated $\mathrm{CRC}$ group included a higher proportion of patients with a history of perianal disease $(73.7 \%$ vs. $50.2 \%, \mathrm{P}=0.035)$ and colonic location $(47.4 \%$ vs. $6.5 \%, \mathrm{P}=0.001)$. Among $19 \mathrm{CD}$-associated CRC patients, 17 (89.5\%) were diagnosed with adenocarcinoma, and of the 17 cases, 15 (88.2\%) were rectal adenocarcinoma. On multivariable analyses for developing CRC, only colonic location was a risk factor (relative risk, 7.735; 95\% confidence interval, 2.862-20.903; $\mathrm{P}=0.001$ ).

Conclusion: Colorectal malignancy is rare among CD patients, even among patients who undergo abdominal surgery. Rectal adenocarcinoma accounted for most of the CRC, and colonic location was a risk factor for developing CRC.

Keywords: Crohn disease; Colorectal neoplasms; Surgery; Outcomes

\section{INTRODUCTION}

Crohn disease (CD) is a major form of inflammatory bowel disease (IBD) that can affect any site along the gastrointestinal tract and often necessitates surgical treatment [1]. Approximately $80 \%$ of patients with CD undergo at least 1 major intestinal surgery during their lifetime [2]. Indications for surgery among CD patients include fistula or abscess formation (50\%), bowel stricture

Received: Jul 26, 2020 - Revised: Oct 22, 2020 - Accepted: Nov 2, 2020 Correspondence to: Jong Lyul Lee, M.D.

Department of Surgery, Asan Medical Center, University of Ulsan College of Medicine, 88 Olympic-ro 43-gil, Songpa-gu, Seoul 05505, Korea

Tel: +82-2-3010-1732, Fax: +82-2-474-6027

E-mail: iamleejong@amc.seoul.kr

ORCID: https://orcid.org/0000-0002-5878-8000

(C) 2021 The Korean Society of Coloproctology

This is an open-access article distributed under the terms of the Creative Commons Attribution NonCommercial License (https://creativecommons.org/licenses/by-nc/4.0) which permits unrestricted noncommercial use, distribution, and reproduction in any medium, provided the original work is properly cited.
(30\%), and bowel perforation (10\%) [3]. Long-term medical treatment is required to prevent complications of $\mathrm{CD}$, postoperatively. Rarely, long-standing CD can be complicated by malignancy [4].

The incidence of malignancy associated with CD is quite low, reportedly ranging between $0.3 \%$ and $0.8 \%$ [5]. Compared with patients from the West, Asian patients with malignant tumors associated with $\mathrm{CD}$ have been reported as more likely to have rectal cancer [6-8]. Korean patients with CD have been found to have higher rates of perianal fistula compared with Western patients, and most colorectal cancer (CRC) that develops from CD is associated with preexisting perianal fistula [9]. Additionally, mucinous cancer accounts for $56.3 \%$ of $\mathrm{CD}$-associated malignancies, and $87.5 \%$ of cases are limited to the anorectal regions [10].

CRCs associated with perianal fistulas are relatively rare, and they tend to occur in patients who have had perianal fistulas for more than 10 years. Abdominoperineal resection (APR) is generally considered to be the surgical treatment of choice for carci- 
noma associated with perianal fistula. There are few articles with small series that describe sporadic cases of perianal cancer associated with $\mathrm{CD}$ fistulas $[11,12]$. When malignancy occurs in association with $\mathrm{CD}$ and perianal fistula, delayed diagnosis, owing to the rareness of the association, can further complicate the scenario. Additionally, there is no clear guidance on how to properly screen for at-risk patients and select the appropriate management strategy. Besides, even when such patients are appropriately and promptly diagnosed, there is still no consensus as to whether they should receive standard treatments, such as preoperative chemotherapy followed by total mesorectal excision, as would administered for patients with sporadic rectal cancer.

This study aimed to evaluate the clinicopathological characteristics as well as the surgical and oncologic outcomes of patients with CD-associated CRC.

\section{METHODS}

\section{Patient's enrollment and variables}

We retrospectively reviewed the medical records of 823 patients who underwent abdominal surgery for $\mathrm{CD}$ at Asan Medical Center, Seoul, Korea, between January 2006 and December 2015. Patients were included if they had undergone bowel resection, strictureplasty, stoma formation, or bypass surgery for $\mathrm{CD}$ during the study period and were 16 years of age or older at the time of surgery. Patients who underwent only stoma restoration were excluded.

CD-associated CRC was defined as malignancy of the colon and rectum that occurred in patients who were diagnosed with $\mathrm{CD}$ and had started medication to treat $\mathrm{CD}$. The study included patients with colorectal adenocarcinoma, lymphoma, and neuroendocrine tumors. We excluded patients who were diagnosed with squamous cell carcinoma originating from the anus, cervical cancer, low-grade dysplasia, and metastatic carcinoma.

The following variables were captured during data collection: demographic and general information (age at diagnosis and operation; sex; duration of disease [duration between $\mathrm{CD}$ diagnosis and the last follow-up]; follow-up period; family history of CD; and history of smoking, perianal disease, abdominal surgery, or perianal surgery), clinical characteristics (Montreal classification and preoperative medications), operative findings (emergency operation, surgical approach, stoma formation, and operation time), operative outcomes (postoperative complications and hospital stay), histopathologic findings (tumor type, differentiation, anatomic association between perianal fistula and tumor, and stage), neoadjuvant or adjuvant treatment (chemotherapy or chemoradiotherapy $[\mathrm{CRT}]$ ), and survival outcome.

\section{Assessment and medical treatment of Crohn disease and the decision to perform surgery \\ Investigations for diagnosing and monitoring $\mathrm{CD}$ included small bowel series, computed tomography (CT) enterography, magnetic}

resonance imaging (MRI), and colonoscopy. Through these tests, the locations affected by $\mathrm{CD}$ could be confirmed, pathological features were evaluated, and, if necessary, surgical findings and postoperative histopathological findings were used for diagnosis [12].

When treating CD patients, a step-up approach is generally used in our institution, which means adding more potent therapies when the first-line or less toxic agents are not effective [13]. Gastroenterologists consult to specialized colorectal surgeons or the multidisciplinary team if a patient requires surgery.

\section{Follow-up and surveillance after treatment of Crohn disease-associated malignancy}

The follow-up schedule for CRC usually proceeded as follows: clinical examinations, laboratory tests including carcinoembryonic agent, abdominopelvic CT every 6 months for the first 3 postoperative years, chest CT every 12 months, and colonoscopy or sigmoidoscopy after 1 postoperative year and then 2 or 3 years later. Patients suspected of recurrence underwent specific examinations (MRI, or positron emission tomography [PET]). Recurrence was diagnosed by radiological and histopathological methods using surgical resection or biopsy specimens [14].

\section{Statistical analysis}

Discrete variables, including demographic and preoperative characteristics, operative methods, and operative details were analyzed using the chi-square test to compare the CD-associated CRC group with the benign $\mathrm{CD}$ group. Continuous variables including, age at surgery, hospital stay, disease duration, and follow-up duration, were compared using unpaired Student t-test or the MannWhitney U-test as appropriate. The overall survival rate was examined using the Kaplan-Meier method and compared using the log-rank test. Multivariable analyses using binary logistic regression were used to assess the risks of developing CRC. Statistical significance was defined as $\mathrm{P}<0.05$, and all statistical analyses were performed using IBM SPSS Statistics for Windows, ver. 21 (IBM Corp., Armonk, NY, USA).

\section{Ethical considerations}

The study protocol was approved by the Institutional Review Board of the Asan Medical Center (No. 2020-0328) with a waiver for informed consent, and the study was performed in accordance with the Declaration of Helsinki.

\section{RESULTS}

\section{Demographic characteristics and clinical features}

A total of 823 patients were finally included in this study. Nineteen patients $(2.3 \%)$ underwent abdominal surgery for CD-associated CRC, and 804 patients (97.7\%) underwent abdominal surgery for benign $\mathrm{CD}$ during the study period. The mean age at the time of surgery among patients in the $\mathrm{CD}$-associated CRC group 
Table 1. Clinical characteristics of the patients with CD-associated CRC and benign CD

\begin{tabular}{|c|c|c|c|}
\hline Variable & CD-associated CRC & Benign CD & P-value \\
\hline No. of patients & 19 & 804 & \\
\hline \multicolumn{4}{|l|}{ Age (yr) } \\
\hline At diagnosis & $29.7 \pm 10.2(23-36)$ & $26.1 \pm 10.0(19-31)$ & 0.150 \\
\hline At operation & $39.2 \pm 11.3(32-49)$ & $31.5 \pm 9.9(24-37)$ & $0.009^{*}$ \\
\hline Sex, female:male & 7 (36.8):12 (63.2) & $233(29.0): 571(71.0)$ & 0.450 \\
\hline Duration of disease (mo) & $124.7 \pm 77.7(66-172)$ & $68.9 \pm 60.2(14-109)$ & $0.006^{*}$ \\
\hline Follow-up period (mo) & $81.7 \pm 39.1(48-107)$ & $85.1 \pm 39.1(59-111)$ & 0.710 \\
\hline Family history of Crohn disease, yes & $0(0)$ & $24(3.0)$ & \\
\hline History of smoking & & & 0.630 \\
\hline None & $11(57.9)$ & $528(65.7)$ & \\
\hline Ex-smoker & $5(26.3)$ & $199(24.8)$ & \\
\hline Current smoker & $3(15.8)$ & $77(9.6)$ & \\
\hline History of perianal disease ${ }^{a}$ & & & $0.035^{\star}$ \\
\hline Yes & $15(78.9)$ & $404(50.2)$ & \\
\hline No & $4(21.1)$ & $400(49.8)$ & \\
\hline History of abdominal surgery & & & $0.001^{*}$ \\
\hline Yes & $11(57.9)$ & $272(33.8)$ & \\
\hline No & $8(42.1)$ & $532(66.2)$ & \\
\hline History of perianal surgery & & & 0.960 \\
\hline Yes & $12(63.2)$ & $332(41.3)$ & \\
\hline No & $7(36.1)$ & $471(58.7)$ & \\
\hline \multicolumn{4}{|l|}{ Montreal classification } \\
\hline Age at diagnosis (yr) & & & 0.990 \\
\hline$\leq 16$ & $2(10.5)$ & $89(11.1)$ & \\
\hline$>16, \leq 40$ & $15(78.9)$ & $639(79.4)$ & \\
\hline$>40$ & $2(10.5)$ & $76(9.5)$ & \\
\hline Behavior at operation & & & $0.001^{*}$ \\
\hline Non-stricturing, non-penetrating (B1) & $8(42.1)$ & $38(4.7)$ & \\
\hline Stricturing (B2) & $6(31.6)$ & $279(34.7)$ & \\
\hline Penetrating (B3) & $5(26.3)$ & $487(60.6)$ & \\
\hline Montreal classification location at operation & & & $0.001^{*}$ \\
\hline Ileum (L1) & $1(5.3)$ & $343(42.7)$ & \\
\hline Colon (L2) & $9(47.4)$ & $52(6.5)$ & \\
\hline Ileocolon (L3) & $9(47.4)$ & $408(50.7)$ & \\
\hline \multicolumn{4}{|l|}{ Medication } \\
\hline No medication or 5-ASA only & $5(26.3)$ & $340(42.5)$ & 0.239 \\
\hline Immunomodulator & $8(42.1)$ & $253(31.5)$ & 0.330 \\
\hline anti-TNF- $\alpha$ & $1(5.3)$ & $48(6.0)$ & 0.990 \\
\hline Steroid & $2(10.5)$ & $41(5.1)$ & 0.260 \\
\hline Immunomodulator with anti-TNF- $\alpha$ & $3(15.8)$ & $57(7.1)$ & 0.070 \\
\hline Immunomodulator with steroid & $0(0)$ & $43(5.3)$ & 0.618 \\
\hline Steroid with anti-TNF- $\alpha$ & $0(0)$ & $8(1.0)$ & 0.990 \\
\hline All combinations & $0(0)$ & $12(1.5)$ & 0.990 \\
\hline
\end{tabular}

Values are presented as number only, mean \pm standard deviation (interquartile range), or number (\%).

CD, Crohn disease; CRC, colorectal cancer; ASA, aminosalicylic acid; anti-TNF- $\alpha$, anti-tumor necrosis factor $\alpha$.

ancluding anal fistula and anal fissure.

${ }^{*} \mathrm{P}<0.05$. 
was significantly older than that among patients in benign group $(39.2 \pm 11.3$ years vs. $31.5 \pm 9.9$ years, $\mathrm{P}=0.002)$. The mean duration of $\mathrm{CD}$ in the $\mathrm{CD}$-associated $\mathrm{CRC}$ group was significantly longer than that in the benign CD group (124.7 \pm 77.7 months vs. $68.9 \pm 60.2$ months, $\mathrm{P}=0.006$ ). The $\mathrm{CD}$-associated $\mathrm{CRC}$ group had significantly higher proportions of patients with a history of perianal disease $(78.9 \%$ vs. $50.2 \%, \mathrm{P}=0.035)$ and abdominal surgery $(57.9 \%$ vs. $33.8 \%, P=0.001)$. Compared with the benign $C D$ group, the $\mathrm{CD}$-associated CRC group had a significantly higher proportion of patients with non-stricturing and non-penetrating (B1) $\mathrm{CD}(42.1 \%$ vs. $4.7 \%, \mathrm{P}=0.001)$, and a significantly lower proportion of patients with penetrating (B3) CD (26.3\% vs. $60.6 \%, \mathrm{P}=0.001$ ), according to the Montreal classification. At the time of surgery, the $\mathrm{CD}$-associated $\mathrm{CRC}$ group had a significantly lower proportion of patients with ileal disease $(5.3 \%$ vs. $42.5 \%$, $\mathrm{P}=0.001$ ) and a significantly higher proportion of patients with colonic disease ( $47.4 \%$ vs. $6.5 \%, \mathrm{P}=0.001)$, compared with the benign $\mathrm{CD}$ group. Variables that did not differ significantly between these 2 groups included age at diagnosis, sex, follow-up duration, family history of $\mathrm{CD}$, history of smoking, history of perianal surgery, age at diagnosis by the Montreal classification, and preoperative medications (Table 1).

Of the 19 patients with CD-associated CRC, 16 (84.2\%) underwent stoma formation procedures (including either permanent or diverting stomas), while 127 benign CD patients (15.8\%) underwent stoma formation procedures $(\mathrm{P}=0.001)$. The mean operating time among patients in the $\mathrm{CD}$-associated $\mathrm{CRC}$ group was significantly longer than that among patients in the benign $\mathrm{CD}$ group ( $250 \pm 123$ minutes vs. $158 \pm 61$ minutes, $\mathrm{P}=0.001)$. The rates of emergency operations, surgical approach, postoperative complications (including infectious and intra-abdominal complications), as well as the mean postoperative hospital stay duration were not significantly different between the 2 groups (Table 2 ).

\section{Clinicopathological characteristics in the Crohn disease- associated CRC group}

Within the CD-associated CRC group, 17 patients (89.5\%) were diagnosed with adenocarcinoma, 1 patient (5.3\%) was diagnosed with a neuroendocrine carcinoma and the other patient (5.3\%) was diagnosed with plasmablastic lymphoma. Seven patients (36.8\%) were already diagnosed with stage IV cancer at the time of diagnosis. Among the 17 patients with colorectal adenocarcinoma, $15(88.2 \%)$ had rectal adenocarcinoma, and $2(11.8 \%)$ had colonic adenocarcinoma (Fig. 1). Ten cases (58.8\%) of colorectal adenocarcinoma were related to an anatomical association between perianal fistula and tumor. Among the 17 patients with colorectal adenocarcinoma, 3 (17.6\%) had poorly-differentiated carcinoma, 5 (29.4\%) had mucinous differentiation, and 3 (17.6 $\%$ ) had signet ring cell carcinoma (unfavorable histology). At the time of surgery, 14 patients (73.7\%) had been diagnosed with CD more than 5 years earlier, and 8 patients (42.1\%) had been diagnosed with CD more than 10 years earlier (Table 3 ).
Table 2. Operative finding and postoperative outcome of the patients with CD-associated CRC and benign CD

\begin{tabular}{lccc}
\hline Variable & $\begin{array}{c}\text { CD-associated } \\
\text { CRC }(\mathrm{n}=19)\end{array}$ & $\begin{array}{c}\text { Benign CD } \\
(\mathrm{n}=804)\end{array}$ & P-value \\
\hline Emergency operation & $1(5.3)$ & $70(8.7)$ & 0.990 \\
Surgical approach & & & 0.780 \\
$\quad$ Open & $16(84.2)$ & $638(79.4)$ & \\
$\quad$ Laparoscopy & $3(15.8)$ & $166(20.6)$ & \\
Stoma formation & & & $0.001^{*}$ \\
Yes & $16(84.2)$ & $127(15.8)$ & \\
No & $3(16.8)$ & $677(84.2)$ & \\
Operation time (min) & $250 \pm 123$ & $158 \pm 61$ & $0.001^{*}$ \\
& $(177-286)$ & $(113-187)$ & \\
Postoperative complication & & & 0.920 \\
Yes & $6(31.6)$ & $202(25.1)$ & \\
No & $13(68.4)$ & $602(74.9)$ & \\
Infectious complication & & & 0.710 \\
Yes & $5(26.3)$ & $152(18.9)$ & \\
No & $14(73.7)$ & $652(81.1)$ & \\
Intraabdominal complication & & & 0.650 \\
Yes & $3(15.8)$ & $77(9.6)$ & \\
No & $16(84.2)$ & $727(90.4)$ & \\
Hospital stay after operation (day) & $16.5 \pm 27.6$ & $13.1 \pm 15.0$ & 0.340 \\
& $(5-21)$ & $(7-13)$ & \\
\hline
\end{tabular}

Values are presented as number (\%) or mean \pm standard deviation (interquartile range).

$\mathrm{CD}$, Crohn disease; CRC, colorectal cancer.

${ }^{*} \mathrm{P}<0.05$.

\section{Operative and oncologic outcomes in the Crohn disease- associated colorectal cancer group}

At the time of diagnosis, 5 patients (26.3\%) whose tumors were inoperable underwent only stoma formation without radical surgery. Eight patients (42.1\%) underwent APR, 3 patients (17.6\%) underwent total colectomy or total proctocolectomy (TPC) due to severe colitis, and 3 patients (17.6\%) underwent segmental resection and anastomosis (right colectomy or low anterior resection). Although more than half of the cases were associated with unfavorable histology, 8 patients (42.1\%) received preoperative or postoperative radiotherapy. A patient was finally diagnosed with pathologic complete remission ( $\mathrm{pCR}$ ) after receiving preoperative CRT, followed by APR (Table 3 ).

The 5-year overall survival rates of the 17 patients with colorectal adenocarcinoma and 15 patients with rectal adenocarcinoma were $52.6 \% \pm 11.5 \%$ and $53.3 \% \pm 13.0 \%$, respectively. One patient with stage IV neuroendocrine carcinoma died within 30 postoperative months, and 1 patient with stage I lymphoma was alive with recurrence after 51 months (Figs. 1,2). One patient with stage IVA colon cancer died within 18 postoperative months, and 


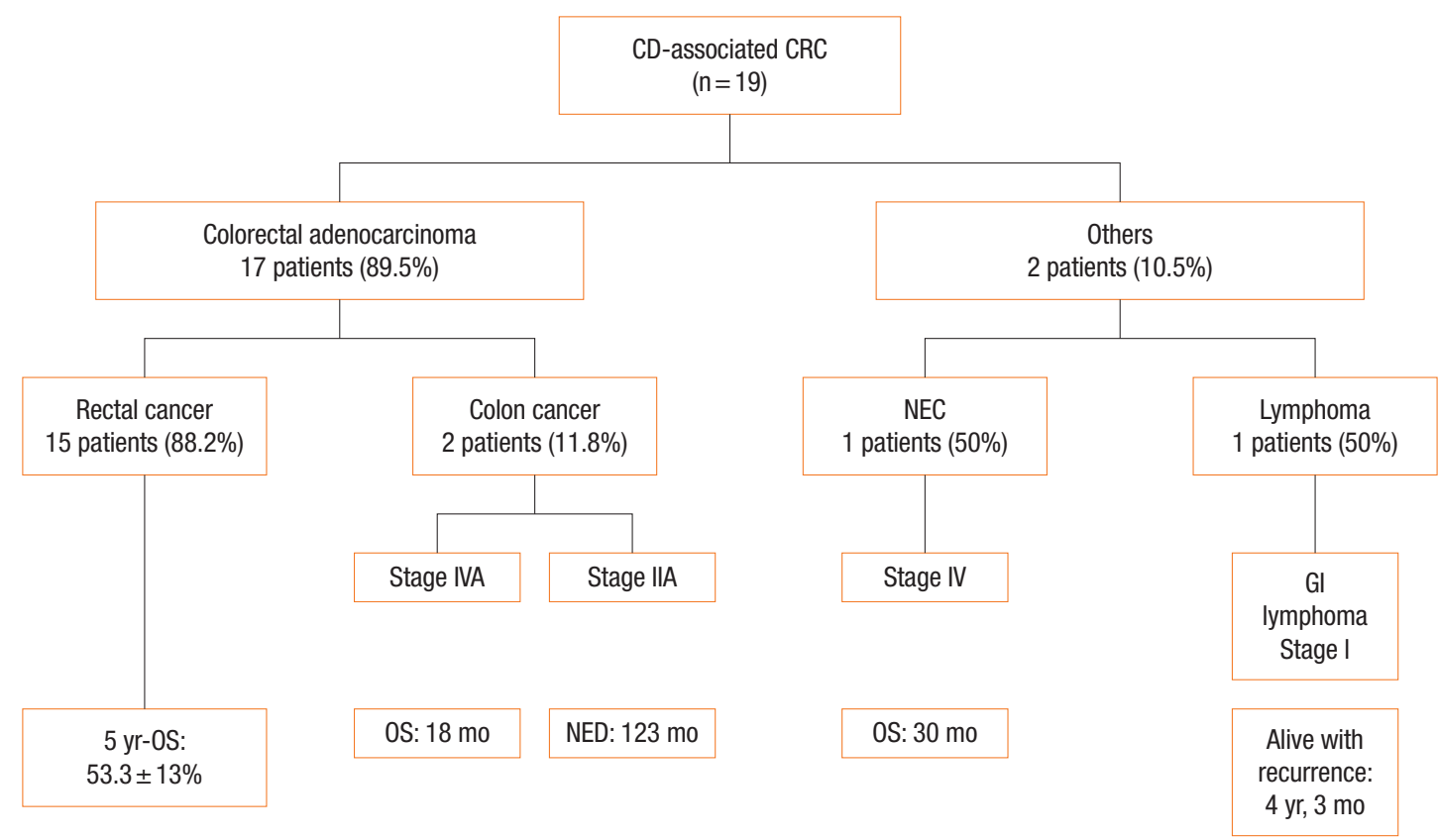

Fig. 1. Classification and survival outcomes of the patients with Crohn disease (CD)-associated colorectal cancer (CRC). NEC, neuroendocrine carcinoma; GI, gastrointestinal; NED, no evidence of disease; OS, overall survival.

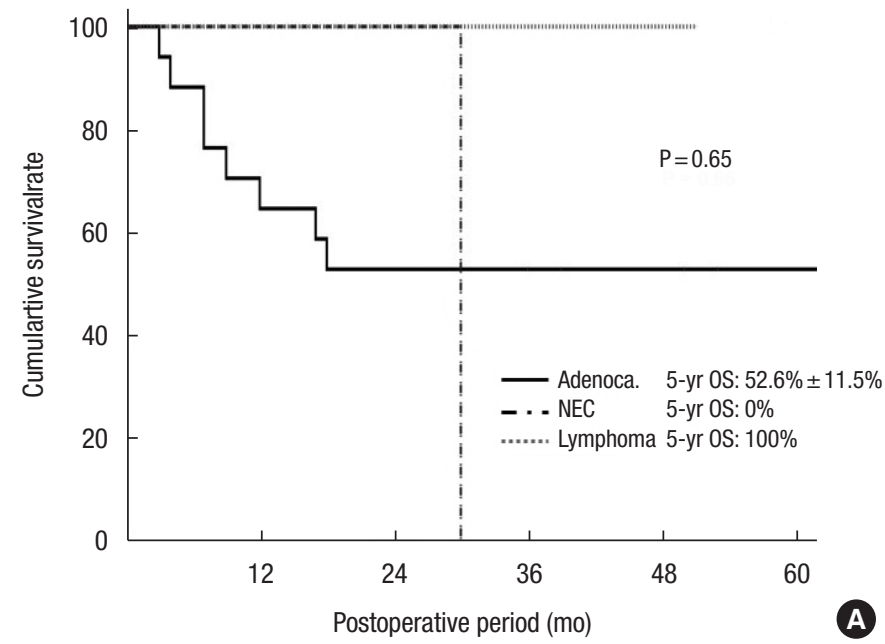

$\begin{array}{lcccccc}\text { Adenoca. } & 17 & 11 & 8 & 8 & 8 & 8 \\ \text { NEC } & 1 & 1 & 1 & 0 & 0 & 0 \\ \text { Lymphoma } & 1 & 1 & 1 & 1 & 1 & 1\end{array}$

No. of patients at risk

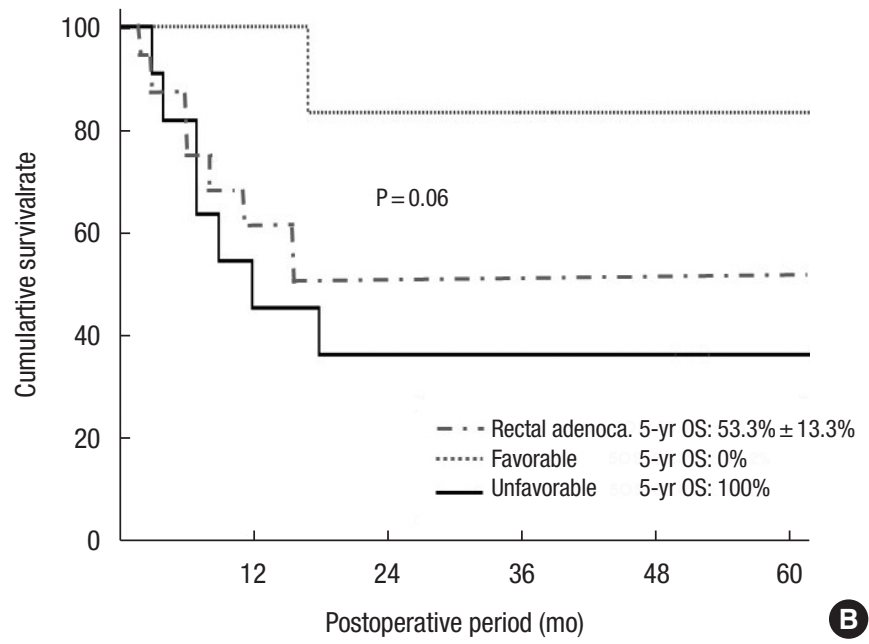

$\begin{array}{lcccccc}\text { Rectal adenoca. } 15 & 9 & 8 & 8 & 8 & 8 \\ \text { Favorable } & 6 & 6 & 5 & 5 & 5 & 5 \\ \text { Unfavorable } & 11 & 5 & 4 & 4 & 4 & 4\end{array}$

No. of patients at risk

Fig. 2. Overall survival (OS) outcome according to tumor type (A) (Adeno., adenocarcinoma; NEC, neuroendocrine carcinoma; Lymphoma) and histologic type (B) (favorable, well-differentiated and moderately-differentiated; unfavorable, poorly-differentiated, mucinous, and signetring cell).

1 patient with stage IIA colon cancer was alive without a recurrence after 123 months (Fig. 1). The 5-year overall survival rate of the 11 patients with unfavorable adenocarcinoma was relatively lower than that of the 6 patients with favorable adenocarcinoma without a significance $(36.4 \% \pm 14.5 \%$ vs. $83.3 \% \pm 15.2 \%, P=0.06)$ (Fig. 2, Supplementary Table 1). Among the 17 patients with adenocarcinoma, 7 patients (41.2\%) remained alive without recurrence at the latest follow-up date. Of 8 patients with regional 
Table 3. Clinicopathological characteristics and survival of the patients with CD-associated colorectal cancer

\begin{tabular}{|c|c|c|c|}
\hline Characteristic & Adenocarcinoma & NEC & Lymphoma \\
\hline No. of patients & 17 & 1 & 1 \\
\hline Sex, female:male & $7(41.2): 10$ (58.8) & $0(0): 1(100)$ & $0(0): 1(100)$ \\
\hline \multicolumn{4}{|l|}{ Age (yr) } \\
\hline At operation & $39.7 \pm 10.3(32-47)$ & 58 & 25 \\
\hline At diagnosis & $30.2 \pm 9.9(24-36)$ & 35 & 14 \\
\hline \multicolumn{4}{|l|}{ Location } \\
\hline Colon & $2(11.8)$ & - & - \\
\hline Rectum & 15 (88.2) & $1(100)$ & $1(100)$ \\
\hline History of perianal fistula & $13(76.5)$ & $1(100)$ & $1(100)$ \\
\hline \multicolumn{4}{|l|}{ Smoking } \\
\hline None & $10(58.8)$ & - & $1(100)$ \\
\hline Ex-smoker & $5(29.4)$ & - & - \\
\hline Current & $2(11.8)$ & $1(100)$ & - \\
\hline \multicolumn{4}{|l|}{ Duration of disease (mo) } \\
\hline$\geq 5 \mathrm{yr}$ & 15 (88.2) & $1(100)$ & $0(0)$ \\
\hline$\geq 10 \mathrm{yr}$ & $11(64.7)$ & $1(100)$ & $0(0)$ \\
\hline \multicolumn{4}{|l|}{ Preoperarive CD medicaiton } \\
\hline Anti-TNF- $a$ only & $1(5.9)$ & $0(0)$ & $0(0)$ \\
\hline Immunomodulator only & $7(41.2)$ & $1(100)$ & $0(0)$ \\
\hline Combination & $3(17.6)$ & $0(0)$ & $1(100)$ \\
\hline $\begin{array}{l}\text { Tumor associated with } \\
\text { perianal fistula }\end{array}$ & $10(58.8)$ & $0(0)$ & $0(0)$ \\
\hline Differentiation or tumor type & & Large cell type & Plasmabalstic \\
\hline WD/MD & $6(35.3)$ & & \\
\hline PD/mucinous/SRC & $11(64.7)$ & & \\
\hline \multicolumn{4}{|l|}{ Operation name } \\
\hline APR & $8(47.1)$ & - & - \\
\hline TC or TPC with stomy & $3(17.6)$ & - & - \\
\hline Stoma with biopsy & $3(17.6)$ & $1(100)$ & $1(100)$ \\
\hline RHC/uLAR with CAA & $2(11.8)$ & - & - \\
\hline \multicolumn{4}{|l|}{ Pathologic stage } \\
\hline $\mathrm{pCR}$ & $1(5.9)$ & - & - \\
\hline I & $3(17.6)$ & - & $1(100)$ \\
\hline$\|$ & $6(35.3)$ & - & - \\
\hline III & $1(5.9)$ & - & - \\
\hline IV & $6(35.3)$ & $1(100)$ & - \\
\hline
\end{tabular}

(Continued to the next)

stages of rectal adenocarcinoma (pCR, stage I, and II), 6 (75.0\%) were alive with $(n=4)$ or without recurrence $(n=2)$.

On additional multivariable analyses for developing CRC, only the $\mathrm{L} 3$ classification (CD colitis) was revealed as a risk factor of
Table 3. Continued

\begin{tabular}{lccc}
\hline Characteristic & Adenocarcinoma & NEC & Lymphoma \\
\hline Additional treatment & $3(17.6)$ & - & - \\
None & $1(5.9)$ & - & - \\
Best supportive care & $3(17.6)$ & - & - \\
Neoadjuvant CCRT & $3(17.6)$ & - & $1(100)$ \\
Adjuvant CTx & $2(11.8)$ & - & - \\
Adjuvant CCRT & $3(17.6)$ & - & - \\
Palliative CTx & $2(11.8)$ & $1(100)$ & - \\
Palliative CCRT & & & \\
Survival & $8(47.1)$ & - & $1(100)$ \\
Yes & $9(52.9)$ & $1(100)$ & - \\
No &
\end{tabular}

Values are presented as number only, number (\%), or mean \pm standard deviation (interquartile range).

$\mathrm{CD}$, Crohn disease; NEC, neuroendocrine carcinoma; anti-TNF- $\alpha$, anti-tumor necrosis factor $\alpha$; WD, well-differentiated; MD, moderately-differentiated; PD, poorlydifferentiated; SRC, signet-ring cell carcinoma; APR, abdominoperineal resection; TC, total colectomy; TPC, total proctocolectomy; RHC, right hemicolectomy; ULAR, ultra-low anterior resection; CAA, coloanal anastomosis; pCR, pathologic complete remission; CCRT, chemoradiotherapy; CTx, chemotherapy.

developing CRC (relative risk, 7.735; 95\% confidence interval, 2.862-20.903; $\mathrm{P}=0.001)$.

\section{DISCUSSION}

The present study showed a CD-associated CRC prevalence of $2.3 \%$ among patients who underwent abdominal surgery for $\mathrm{CD}$. Unsurprisingly, this prevalence was higher than that of the general $\mathrm{CD}$ population, as the present study included patients who had abdominal surgery. Although there has been some controversy regarding the increased risk of developing cancer in association with CD since the first report of CD-associated CRC in 1948 [15], a population-based study demonstrated an increased risk of $\mathrm{CRC}$, and a recent meta-analysis also showed CD patients have a 2.4-fold overall increased risk of developing CRC [16-18]. A study reported that, among $\mathrm{CD}$ patients, the cumulative incidence of CRC was $0.3 \%$ at 5 years, $1.6 \%$ at 15 years, and $2.4 \%$ at 25 years, and a cross-sectional comparison revealed a $1.9 \%$ increased risk of CD-associated CRC, which is similar to the results of the present study [19]. From the literature, this relatively high prevalence supports that inflammation plays an important role in the development of CRC, especially considering that CD patients who have undergone surgery are usually affected by more active disease and longer duration $[20,21]$.

The present study demonstrated the association between the anatomic location of the $\mathrm{CD}$ involvement and the development of CRC. The CD-associated CRC group had a significantly higher 
rate of perianal fistula history, and more than half of the CD-associated CRC had an anatomical association between perianal fistula and tumor. There have been some reports of fistula-associated CRC in CD patients, and those reports also suggested a possible association between perianal fistula and CRC $[9,11,22]$. A review article showed the correlation between colitis (inflammation) and cancer risk and discussed how inflammation might contribute to CRC pathogenesis (inflammation-dysplasia-cancer model) [23]. Similarly, the present study showed that the L3 classification (CD colitis) was revealed as a risk factor for developing $\mathrm{CD}$-associated CRC. Smoking and long-standing disease duration have also been found to be independent risk factors for developing $\mathrm{CRC}$ among $\mathrm{CD}$ patients $[24,25]$. Because smoking rate of both groups in the present is low, it seems difficult to determine whether smoking is a risk factor for CRC. Although the mean disease duration of the CD-associated CRC group was significantly longer than that of the benign CD group, the present study did not show that disease duration was a risk factor for developing CRC. However, considering that more than $40 \%$ of CD-associated patients have been $\mathrm{CD}$ for more than 10 years, the present study might suggest that physicians should be alerted to the possibility of CRC when they observe perianal fistula or CD colitis with long-standing $\mathrm{CD}$ duration.

Surgery for CD-associated CRC is complicated by the conflicting objectives of minimal bowel resection and appropriate tumor resection. For CD-associated CRC, American Society of Colon and Rectal Surgery clinical practice guidelines insist on TPC for multiplicity and to reduce the risk of metachronous CRC [26]. Although the extent of resection required can depend on the location of the malignancy, it is notable that multifocal dysplasia is observed in more than one-third of specimens from patients who have undergone colectomy [27]. Besides, $14 \%$ to $40 \%$ of the patients who undergo segmental resection for cancer of the large intestine develop metachronous colorectal cancers, which supports the call for TPC for CD-associated CRC [27, 28]. However, only $17 \%$ of the patients in the present study underwent total colectomy or TPC, partly because $40 \%$ of the patients had inoperable disease at the time of diagnosis; surgeon preferences also played a role in the low proportion of total colectomy and TPC. The present study also found no metachronous CRC or multiplicity in the specimens, so further research is needed, as the follow-up duration was relatively short.

Although a high rate of stage IV CRC was observed in the present study, patients with early stage (pCR, stage I, and stage II) and favorable histology had a relatively good 5-year overall survival rate. This finding highlights the importance of early detection in terms of facilitating good oncologic outcomes. However, it is difficult to diagnose fistula-associated CRC because it is difficult to distinguish malignancy from $\mathrm{CD}$ colitis in perianal fistulas. In general, symptoms of CD-associated CRC are non-specific, and the sensitivity of the imaging test (CT, MRI, and PET) is relatively low owing to inflammation, and this can lead to delayed diagnosis
$[9,29,30]$. Patients with a long-term history of perianal fistula have been found to have high cancer stages at the time of surgery $[11,31]$. For managing perianal fistulas, early detection of CRC, and managing CD-associated CRC, it is ideal to use a multidisciplinary team approach including gastroenterologists, colorectal surgeons, oncologists, and radiologists.

The prognosis of $\mathrm{CD}$-associated CRC patients after surgery is largely determined by the CRC stage after surgery [32]. The present study showed that prognosis, histologic type, and stage were related, it was encouraging that there was a patient who went into pCR after receiving preoperative CRT. In terms of quality of life, the rate of stoma formation was more than $80 \%$ in the present study, and this was related to the anatomical association between perianal fistula and tumor and poor outcomes associated with pouch surgery in $\mathrm{CD}$ [33]. From these results, it is apparent that a multimodality approach incorporating early detection and appropriate surgery and CRT may produce good functional and oncologic results even in patients with CD-associated CRC.

Because the present study was retrospective and cross-sectional in design, we could not control for clinicopathological characteristics. However, the study evaluated both CD-associated CRC and benign $\mathrm{CD}$ characteristics, including demographics, surgical methods, pathologic findings, and postoperative and oncologic outcomes, using a relatively large patient cohort. Another limitation of this study was the lack of analysis of risk factors for developing CRC in association with $\mathrm{CD}$ due to the small number of CD-associated CRC patients. Nevertheless, the present study was meaningful, as it included a larger number of patients than other retrospective studies, and it clarified the prevalence of $\mathrm{CD}$-associated $\mathrm{CRC}$ among patients who underwent abdominal surgery.

In conclusion, the diagnosis of colorectal malignancy is rare among $\mathrm{CD}$ patients who have undergone abdominal surgery and the L3 classification (CD colitis) was a risk factor of developing CRC. Rectal adenocarcinoma accounted for most of the CRC, and the subgroup with unfavorable histology had poor overall survival rate.

\section{CONFLICT OF INTEREST}

No potential conflict of interest relevant to this article was reported.

\section{SUPPLEMENTARY MATERIALS}

Supplementary materials for this study are presented online (available at https://doi.org/10.3393/ac.2020.11.02).

\section{REFERENCES}

1. Bernell O, Lapidus A, Hellers G. Risk factors for surgery and recurrence in 907 patients with primary ileocaecal Crohn's disease. Br J Surg 2000;87:1697-701. 
2. Mills S, Stamos MJ. Colonic Crohn's disease. Clin Colon Rectal Surg 2007;20:309-13.

3. Lewis RT, Maron DJ. Efficacy and complications of surgery for Crohn's disease. Gastroenterol Hepatol (N Y) 2010;6:587-96.

4. Cahill C, Gordon PH, Petrucci A, Boutros M. Small bowel adenocarcinoma and Crohn's disease: any further ahead than 50 years ago? World J Gastroenterol 2014;20:11486-95.

5. Laukoetter MG, Mennigen R, Hannig CM, Osada N, Rijcken E, Vowinkel T, et al. Intestinal cancer risk in Crohn's disease: a metaanalysis. J Gastrointest Surg 2011;15:576-83.

6. Bernstein D, Rogers A. Malignancy in Crohn's disease. Am J Gastroenterol 1996;91:434-40.

7. Gillen CD, Andrews HA, Prior P, Allan RN. Crohn's disease and colorectal cancer. Gut 1994;35:651-5.

8. Kim J, Lee HS, Park SH, Yang SK, Ye BD, Yang DH, et al. Pathologic features of colorectal carcinomas associated with Crohn's disease in Korean population. Pathol Res Pract 2017;213:250-5.

9. Ogawa H, Haneda S, Shibata C, Miura K, Nagao M, Ohnuma S, et al. Adenocarcinoma associated with perianal fistulas in Crohn's disease. Anticancer Res 2013;33:685-9.

10. Lee KM, Lee JM. Crohn's disease in Korea: past, present, and future. Korean J Intern Med 2014;29:558-70.

11. Iesalnieks I, Gaertner WB, Glass H, Strauch U, Hipp M, Agha A, et al. Fistula-associated anal adenocarcinoma in Crohn's disease. Inflamm Bowel Dis 2010;16:1643-8.

12. Connell WR, Sheffield JP, Kamm MA, Ritchie JK, Hawley PR, Lennard-Jones JE. Lower gastrointestinal malignancy in Crohn's disease. Gut 1994;35:347-52.

13. Sobala A, Herbst F, Novacek G, Vogelsang H. Colorectal carcinoma and preceding fistula in Crohn's disease. J Crohns Colitis 2010;4:189-93.

14. Yang KM, Yu CS, Lee JL, Kim CW, Yoon YS, Park IJ, et al. Risk factors for postoperative recurrence after primary bowel resection in patients with Crohn's disease. World J Gastroenterol 2017; 23:7016-24.

15. Warren S, Sommers SC. Cicatrizing enteritis as a pathologic entity; analysis of 120 cases. Am J Pathol 1948;24:475-501.

16. Persson PG, Karlén P, Bernell O, Leijonmarck CE, Broström O, Ahlbom A, et al. Crohn's disease and cancer: a population-based cohort study. Gastroenterology 1994;107:1675-9.

17. Greenstein AJ, Sachar DB, Smith H, Janowitz HD, Aufses AH Jr. A comparison of cancer risk in Crohn's disease and ulcerative colitis. Cancer 1981;48:2742-5.

18. von Roon AC, Reese G, Teare J, Constantinides V, Darzi AW, Tekkis PP. The risk of cancer in patients with Crohn's disease. Dis Colon Rectum 2007;50:839-55.

19. Jess T, Loftus EV Jr, Velayos FS, Harmsen WS, Zinsmeister AR, Smyrk TC, et al. Risk of intestinal cancer in inflammatory bowel disease: a population-based study from olmsted county, Minnesota. Gastroenterology 2006;130:1039-46.

20. Scaringi S, Di Martino C, Zambonin D, Fazi M, Canonico G, Leo F, et al. Colorectal cancer and Crohn's colitis: clinical implications from 313 surgical patients. World J Surg 2013;37:902-10.

21. Maykel JA, Hagerman G, Mellgren AF, Li SY, Alavi K, Baxter NN, et al. Crohn's colitis: the incidence of dysplasia and adenocarcinoma in surgical patients. Dis Colon Rectum 2006;49:950-7.

22. Shwaartz C, Munger JA, Deliz JR, Bornstein JE, Gorfine SR, Chessin DB, et al. Fistula-associated anorectal cancer in the setting of Crohn's disease. Dis Colon Rectum 2016;59:1168-73.

23. Itzkowitz SH, Yio X. Inflammation and cancer IV. Colorectal cancer in inflammatory bowel disease: the role of inflammation. Am J Physiol Gastrointest Liver Physiol 2004;287:G7-17.

24. Tsoi KK, Pau CY, Wu WK, Chan FK, Griffiths S, Sung JJ. Cigarette smoking and the risk of colorectal cancer: a meta-analysis of prospective cohort studies. Clin Gastroenterol Hepatol 2009;7:682-8.

25. Sjödahl RI, Myrelid P, Söderholm JD. Anal and rectal cancer in Crohn's disease. Colorectal Dis 2003;5:490-5.

26. Strong S, Steele SR, Boutrous M, Bordineau L, Chun J, Stewart $\mathrm{DB}$, et al. Clinical practice guideline for the surgical management of crohn's disease. Dis Colon Rectum 2015;58:1021-36.

27. Kiran RP, Nisar PJ, Goldblum JR, Fazio VW, Remzi FH, Shen B, et al. Dysplasia associated with Crohn's colitis: segmental colectomy or more extended resection? Ann Surg 2012;256:221-6.

28. Maser EA, Sachar DB, Kruse D, Harpaz N, Ullman T, Bauer JJ. High rates of metachronous colon cancer or dysplasia after segmental resection or subtotal colectomy in Crohn's colitis. Inflamm Bowel Dis 2013;19:1827-32.

29. Devon KM, Brown CJ, Burnstein M, McLeod RS. Cancer of the anus complicating perianal Crohn's disease. Dis Colon Rectum 2009;52:211-6.

30. Basseri RJ, Basseri B, Vassilaki ME, Melmed GY, Ippoliti A, Vasiliauskas EA, et al. Colorectal cancer screening and surveillance in Crohn's colitis. J Crohns Colitis 2012;6:824-9.

31. Thomas M, Bienkowski R, Vandermeer TJ, Trostle D, Cagir B. Malignant transformation in perianal fistulas of Crohn's disease: a systematic review of literature. J Gastrointest Surg 2010;14:6673.

32. Ueda T, Inoue T, Nakamoto T, Nishigori N, Kuge H, Sasaki Y, et al. Anorectal cancer in Crohn's disease has a poor prognosis due to its advanced stage and aggressive histological features: a systematic literature review of Japanese patients. J Gastrointest Cancer 2020;51:1-9.

33. Le Q, Melmed G, Dubinsky M, McGovern D, Vasiliauskas EA, Murrell Z, et al. Surgical outcome of ileal pouch-anal anastomosis when used intentionally for well-defined Crohn's disease. Inflamm Bowel Dis 2013;19:30-6. 